\title{
Paroxysmal Nocturnal Hemoglobinuria: A Chronic Rare Acquired Hemolytic Anemia in a Middle-aged Female with Thrombotic Complications and Multi-system Involvement
}

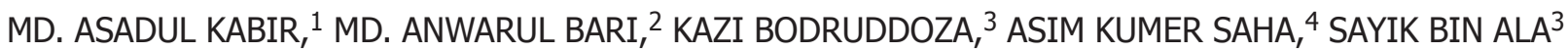

\begin{abstract}
:
Paroxysmal Nocturnal Hemoglobinuria (PNH) is an acquired coomb's negative hemolytic anemia, the hallmark of which is chronic intravascular hemolysis, thrombophilia and their sequelae owing to the deficiency of several surface proteins on blood cell membranes. In this case a middle-aged female presents with severe anemia requiring repeated blood transfusion and recurrent deep vein thrombosis (DVT). She had been hospitalized in multiple occasions in multiple centers without any satisfactory diagnosis. The constant laboratory features were that of hemolytic anemia, thrombocytopenia and a negative coomb's test; although reticulocyte count had not been elevated. Lastly Blood flow cytometry revealed PNH clones. Although excellent improvement of the clinical features of PNH can be achieved by treatment with Eculizumab, we could not offer that to our patient due to its unavailability in Bangladesh. She was discharged with advice for Hematopoietic Stem Cell Transplantation (HSCT) after her symptoms improved with symptomatic management. High degree of suspicion and appropriate application of clinical knowledge is necessary to make such a diagnosis early in the disease process, for prompt initiation of treatment and thus minimizing complications.
\end{abstract}

Key words: Paroxysmal Nocturnal Hemoglobinuria, Intravascular hemolysis, Eculizumab, HSCT.

\section{Introduction:}

Paroxysmal Nocturnal Hemoglobinuria $(\mathrm{PNH})$ is a rare Acquired Hemolytic anemia with multisystem involvement, in which certain proteins are deficient not only on RBC membrane but also on all three blood cell membranes that cause unchecked amplification of the complement activation process and the resultant intravascular hemolysis and its consequences, manifesting as hemolytic anemia, thrombocytopenia, pancytopenia, thrombotic and other complications. ${ }^{1,2,3}$ As those proteins are deficient in $\mathrm{PNH}$, there is unchecked complement activation, intravascular hemolysis, hemoglobinuria, vasospasm, pulmonary hypertension, venous and arterial thrombosis and their complications. Patients might present with recurrent DVT, severe anemia, pulmonary hypertension and its complications, hepato- and/or splenomegaly, splenic,

1. Associate Professor, Department of Medicine, SSMC \& MH, Dhaka.

2. Assistant Professor, Department of Medicine, SSMC \& MH, Dhaka.

3. Post graduate trainee, Department of Medicine, SSMC \& MH, Dhaka.

4. Assistant Registrar, Department of Medicine, SSMC \& MH, Dhaka.

Corresponding author: Dr. Md. Asadul Kabir, Associate Professor, Department of Medicine, SSMC \& MH, Dhaka. Phone: +8801711231950 Email: chapalk40@yahoo.com. mesenteric or hepatic vein thrombosis (Budd-Chiari Syndrome). There may be bone marrow aplasia even when the peripheral blood counts are normal. The ideal treatment would be Hematopoietic Stem Cell Transplantation (HSCT) but that itself is associated with significant mortality and morbidity. A recently approved humanized monoclonal antibody, Eculizumab, is shown to halt hemolysis and improve symptoms and prevent development of complications. ${ }^{4}$

Here we report a case of Paroxysmal Nocturnal Hemoglobinuria with its clinical features and complications, diagnostic works, management perspectives and shortcomings that will help our clinicians in early diagnosis and treatment in their clinical practice.

\section{Case Report:}

A 30-year-old Muslim housewife was admitted in a tertiary hospital on $7^{\text {th }}$ September 2015 with the complaints of breathlessness on exertion, cough, generalized weakness and swelling of legs for 2 months. She experienced gradually increasing shortness of breath on walking for few steps, which worsened on lying flat and caused disturbance of sleep on several occasions. Cough was not associated with sputum production or chest pain, neither did she have any history of asthma or COPD. On admission there was bilateral pitting edema and tenderness in right cuff muscles. She had history 
of hospital admissions on several occasions prior to this. In April 2015, she was admitted due to history of chest pain, fever, cough, headache, vomiting and leg pain for 3 weeks. She was diagnosed as case of Pneumonia with Extrapulmonary complications (Hematological, Neurological) with DVT with ITP with Severe Anemia with Bilateral Sixth nerve palsy and Retinal Hemorrhage. She was treated with Antibiotics, a short course of low molecular weight heparin (LMWH) and other symptomatic management at that time and was discharged as her pneumonia and other manifestations resolved. In August 2015 she was again admitted and was treated as a case of heart failure and pulmonary hypertension (on the basis of Echocardiography report). The patient had no history of dysuria, dyspepsia, bowel/ bladder disturbance, jaundice, rash, joint pain, oral ulcer or sore throat.

On examination, she was severely anemic, JVP was raised and had bilateral pitting oedema (more on right) with right cuff muscle tenderness. Her respiratory rate was $20 / \mathrm{min}$, pulse rate was $96 \mathrm{~b} / \mathrm{m}$, temperature was $98^{\circ} \mathrm{F}$ and blood pressure was $100 / 60 \mathrm{mmHg}$. On auscultation there was bilateral basal crepitation. Palpable P2 \& Right parasternal heave were present. Other systemic examination, Including nervous, musculoskeletal and alimentary system revealed no abnormality. Fundoscopy showed right sided macular edema.

Complete Blood Count done in this admission showed Hemoglobin $5.8 \mathrm{mg} / \mathrm{dL}$, Total Leucocyte count 7000/ cumm, Platelet count 1,60,000/ cumm and ESR was $>140 \mathrm{~mm}$ in $1^{\text {st }}$ hour. CBC done on several occasion at past showed severe anemia and normal leucocyte count. Her MCV in this occasion was elevated $113.9 \mathrm{fL}$, but in previous results it was within normal limit. Though previous blood films showed varying degrees of normocytic/macrocytic anemia, neutrophilia and thrombocytopenia, PBF on this occasion showed spherocytes, polychromatic macrocytes, nucleated $\mathrm{RBCs}$ and roleux formation consistent with autoimmune hemolytic anaemia (AIHA). Serum bilirubin was $1.9 \mathrm{mg} / \mathrm{dL}$ (direct 0.7 and indirect $1.2 \mathrm{mg} / \mathrm{dL}$ ). Previous reticulocyte count, Coombs test, ANA, pANCA, cANCA and AntidsDNA results were normal. Bone marrow examination done in April 2015 was consistent with Immune Thrombocytopenic Purpura.

Echocardiogram done in September'15 revealed MR (Gr I), TR (Gr - I), PR (Gr - II), Moderate Pulmonary Hypertension with RVH, Good LV systolic function (EF 68\%), PASP: $50 \mathrm{mmHg}$, PADP: $34 \mathrm{mmHg}$. Duplex Ultrasound of lower limb vessels done in April '15 showed subacute DVT involving distal right superficial, whole of popliteal and proximal parts of posterior and anterior and posterior tibial veins with signs of minimal recanalization and sapheno-popliteal junction was obscured by thrombus. The study done in August'15 yielded normal study. LDH was $977 \mathrm{U} / \mathrm{L}$ and D-dimer in this admission was $3.62 \mathrm{ug} / \mathrm{mL}$ whereas in April it was $>4 \mathrm{ug} / \mathrm{mL}$. Chest X-ray showed full pulmonary conus with clear lung fields; though varying degrees of pleural effusion were present in previous ones. USG of whole abdomen revealed trace ascites, splenomegaly, and mild pleural effusion.

Her hemolytic anemia and all the features could not be explained by a unifying diagnosis despite repeated hospital admissions. PNH was a possibility considering the coomb's test negative hemolytic anemia, thrombocytopenia and thrombophilia. So, Blood Flow Cytometry was done which revealed $\mathrm{PNH}$ clone in $70.30 \%$ of WBCs and $25.6 \%$ of RBCs which is consistent with a diagnosis of Paroxysmal nocturnal hemoglobinuria.

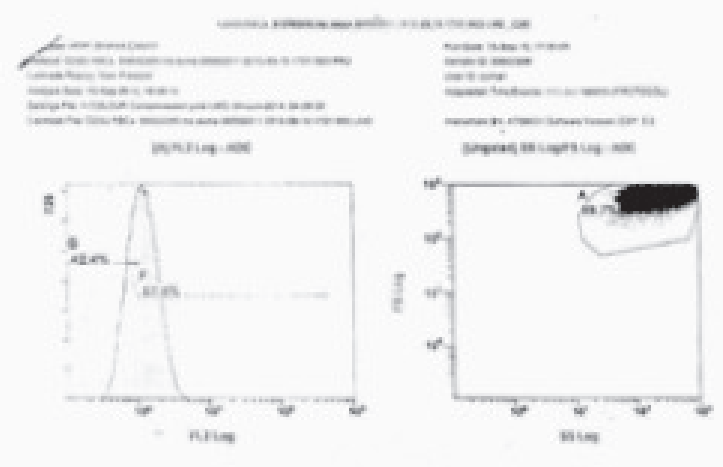

Fig.-1: CD55 RBC distribution curve in this patient, flow cytometric analysis.

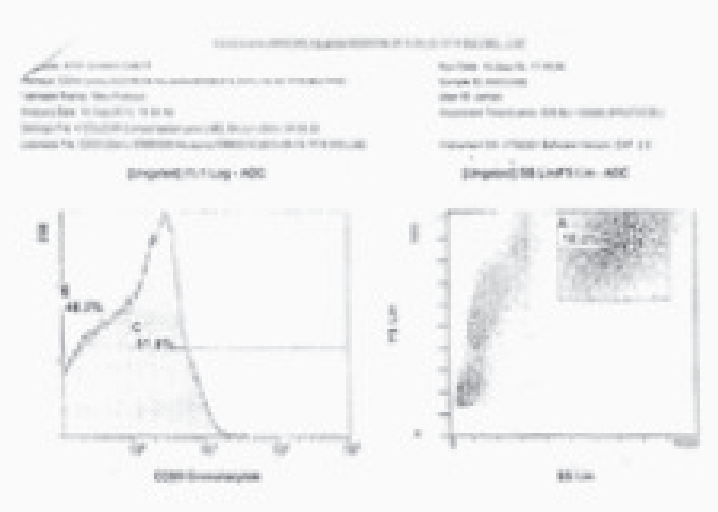

Fig.-2: CD59 Granulocyte distribution curve in this patient, flow cytometric analysis. 
She was being treated with Antibiotics, Ambrisentan and Sildenafil for her pulmonary hypertension and LMWH to help her current DVT features. Her symptoms improved with these treatment and she was subsequently discharged in stable and symptom free conditions with further advice for HSCT. Although according to current guidelines the first treatment that should be offered is Eculizumab, it is not available in Bangladesh and the patient party is not well off enough to afford treatment in abroad.

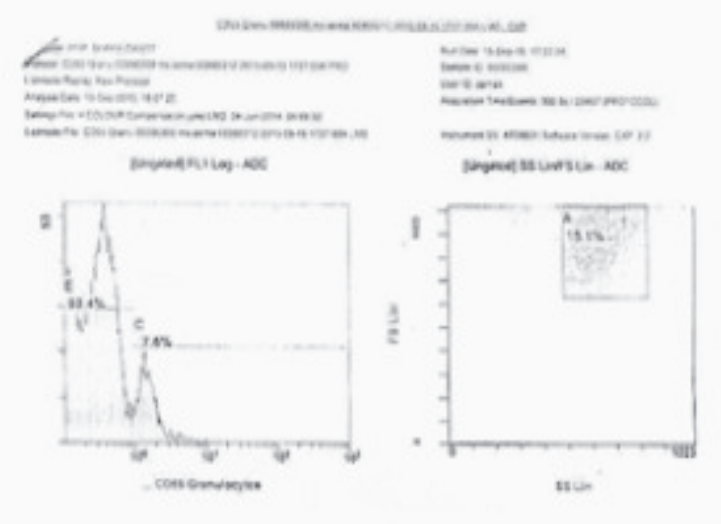

Fig.-3: CD59 Granulocyte distribution curve in this patient, flow cytometric analysis.

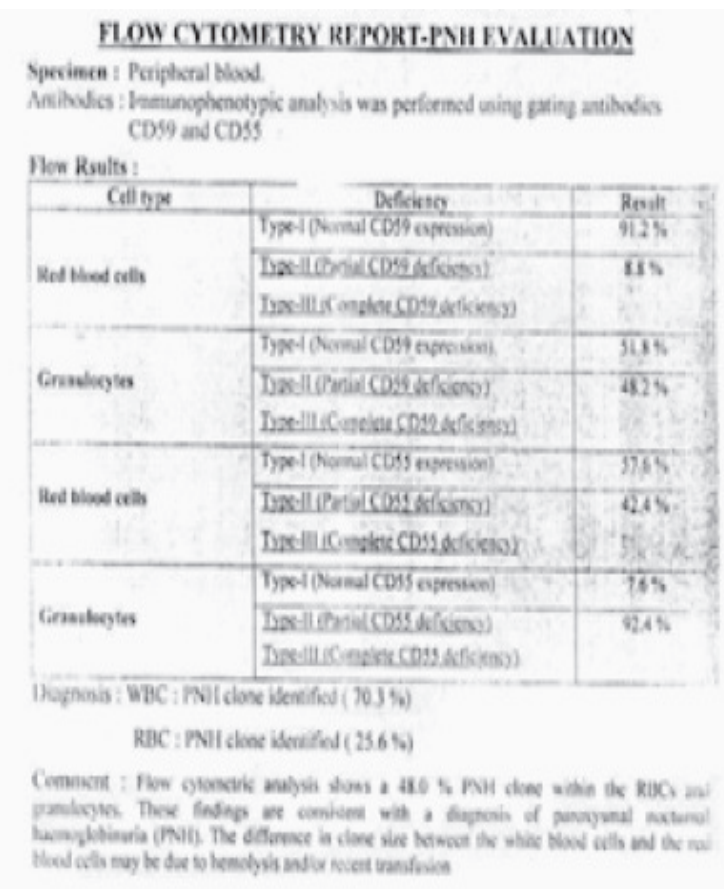

Figu.-4: Report of Flow Cytometric Analysis of patients blood for CD59 \& CD55 deficient clone.

\section{Discussion:}

Paroxysmal Nocturnal Hemoglobinuria is known to be a rare acquired hemolytic anemia in which RBCs undergo chronic persistent complement mediated hemolysis owing to the deficiency on its membrane of several important proteins which in normal conditions happen to halt the process of complement activation. Later it was found out that those proteins are missing in other cells of blood as well as RBCs. No hereditary case has been reported and prevalence is equal in men and women. The biochemical defect is a genetic mutation that inhibits the synthesis of Glycosylphosphatidylinositol (GPI) anchor that binds these proteins to cell membranes. The gene responsible is the PIG-A (Phosphatidylinositol Glycan Class A) gene on the $\mathrm{X}$ chromosome, and there is substantial variability in the pattern of mutation in the gene from patient to patient. 5 The membrane proteins that are deficient in $\mathrm{PNH}$ are complement -regulating surface proteins and includes CD55 (Decay Accelerating Factor; DAF), CD59 (Membrane Inhibitor of Reactive Lysis; MIRL) and C8 binding protein (Homologous Restriction Factor; HRF). These proteins interact with complement proteins, particularly $\mathrm{C} 3 \mathrm{~b}$ and $\mathrm{C} 4 \mathrm{~b}$, and inhibits the complement activation process. Most important of these is CD59, which hinders the insertion into the membrane of C9 polymers. The absence of these proteins causes unchecked amplification of the complement activation process and consequent cell lysis. The clinical features of PNH are more or less all related to the cell lysis. Lysis of RBC causes hemolytic anemia, which may be mild, moderate or severe at presentation, the hemoglobin that is released due to intravascular hemolysis depletes serum haptoglobin and remaining free hemoglobin goes on to be excreted by the kidneys with the urine (hence the name hemoglobinuria), which in the longer term can cause chronic renal failure.

The free hemoglobin also binds irreversibly to Nitric Oxide and depletes NO in peripheral blood, causing vasospasm with resultant gut ischemia, pulmonary hypertension and other vasospastic complications. ${ }^{7}$

One of the most prominent presenting features in $\mathrm{PNH}$ is thrombophilia, the mechanism of which has yet not been delineated fully. Patients present with thrombotic symptoms ranging from DVT to hepatic and mesenteric vein thrombosis (e.g. Budd-Chiari syndrome) to cerebro-vascular accidents. ${ }^{8-}$

${ }^{10}$ Pulmonary hypertension in PNH can be either due to NO depleted state or due to widespread formation of thrombuses in pulmonary microvasculature. ${ }^{11}$ In our patient however, the possibility of chronic pulmonary thromboembolism could not be excluded as CTPA was not done.

Varying degrees of Bone Marrow Failure is almost always present in patients with $\mathrm{PNH}$. 10-20\% patients with $\mathrm{PNH}$ 
goes on to develop Aplastic Anemia and 5\% patients with aplastic anemia develops PNH. The relation between these and the pathogenesis is not yet fully elucidated. ${ }^{12,13}$

Patients present with passage of dark red urine - specially in the morning, features of thrombosis and the presentation can be varied. There may be varying degrees of anemia, thrombocytopenia, markedly elevated LDH level, increased Reticulocyte count, elevated serum bilirubin - specially the indirect fraction, decreased level of serum Haptoglobin. Anemia may be normo-macrocytic or may be microcytic if the patient is iron deficient. Bone marrow may show erythroid hyperplasia with varying degrees of dyserythropoietic features. In the long run bone marrow may become hypocellular or frankly aplastic.

The acidified serum (Ham) test is highly reliable in making a definitive diagnosis but the gold standard now is Blood Flow cytometry. ${ }^{14-17}$ If 5\% or more RBCs and $20 \%$ or more granulocytes are CD59 and CD55 deficient, the diagnosis of PNH can be definitively made. ${ }^{18}$

Apart from symptomatic management with blood transfusion, antithrombotic prophylaxis, pulmonary hypertension management, the definitive curative treatment is Allogenic Hematopoietic Stem Cell Transplantation (HSCT). ${ }^{19,20}$ But HSCT itself carries risks of transplant related mortality of $42 \%$ and graft failure in $8 \%$ cases. $^{21}$ The availability of HLA-matched donor is also a concern. With advent of a new drug, approved in 2007, namely Eculizumab, which is a humanized monoclonal antibody against complement component $\mathrm{C} 5$, the indication for allogenic HSCT has changed significantly. ${ }^{22-25}$ The initial treatment of patients with classic PNH should be Eculizumab, which shows significant reduction in mortality and morbidity, rate of hemolysis and development of thrombotic complications. There are concerns regardiong increased susceptibility of infection specially Neisseria meningitides for which prophylactic vaccination with tetravalent meningococcal vaccine is indicated. There is also small risk of developing meningococcal septicemia in vaccinated patients for which prophylactic antibiotic therapy with Penicillin or Erythromycin is indicated. ${ }^{26-28}$

Paroxysmal Nocturnal Hemoglobinuria was first described in $18^{\text {th }}$ century. "Paroxysmal" "nocturnal" hemoglobinuria is a misnomer in the sense that, it is now well known that the hemolysis and resultant hemoglobinuria is neither 'paroxysmal' nor purely 'nocturnal'. Hemolysis occurs throughout the day and the passage of dark coloured urine in the morning is due to overnight increment in concentration of hemoglobin in urine. There is persistent amplification of complement cascade activation via the alternative pathway in $\mathrm{PNH}$ and there can be 'paroxysmal' acceleration of complement activation and hemolysis during a course of viral or bacterial infection through an antigen-antibody reaction. ${ }^{18}$

$\mathrm{PNH}$ is a multifaceted disease that has the potential for significant mortality, morbidity and can drastically reduce the quality of life in affected patients. Appropriate awareness of the rare condition among clinicians is therefore of paramount importance.

\section{Conlict of interest: None.}

\section{References:}

1. Rosti V. The molecular basis of paroxysmal nocturnal hemoglobinuria. Haematologica. 2000 Jan;85(1):82-7.

2. Brodsky RA. Paroxysmal Nocturnal Hemoglobinuria: Stem Cells and Clonality. Hematology. 2008;1:111-115.

3. Kawagoe K, Kitamura D, Okabe M, Taniuchi I, Ikawa M, Watanabe T, Kinoshita T, Takeda J. Glycosylphosphatidylinositol-anchor-deficient mice: implications for clonal dominance of mutant cells in paroxysmal nocturnal hemoglobinuria. Blood. 1996;87(9):3600-6.

4. Hillmen P, Young NS, Schubert J, Brodsky RA, Socié G et al. The Complement Inhibitor Eculizumab in Paroxysmal Nocturnal Hemoglobinuria. N Engl J Med 2006;355:123343.

5. See comment in PubMed Commons belowBrodsky RA, Hu R. PIG-A mutations in paroxysmal nocturnal hemoglobinuria and in normal hematopoiesis. Leuk Lymphoma. 2006;47(7):1215-2.

6. Parker CJ. Molecular basis of paroxysmal nocturnal hemoglobinuria. Stem Cells. 1996;14(4):396-411.

7. Schaer DJ, Buehler PW. Cell-free hemoglobin and its scavenger proteins: new disease models leading the way to targeted therapies. Cold Spring Harb Perspect Med. 2013;3(6).

8. Ray JG, Burows RF, Ginsberg JS, Burrows EA. Paroxysmal nocturnal hemoglobinuria and the risk of venous thrombosis: review and recommendations for management of the pregnant and nonpregnant patient. Haemostasis. 2000;30(3):103-17.

9. Araten DJ, Notaro R, Thaler HT, Kernan N, Boulad F, Castro-Malaspina H, Small T, Scaradavou A, Magnan H, Prockop S, Chaffee S, Gonsky J, Thertulien R, Tarquini R, Luzzatto L. Thrombolytic therapy is effective in paroxysmal nocturnal hemoglobinuria: a series of nine patients and a review of the literature. Haematologica. 2012 Mar;97(3):34452.

10. Zou N, Han B, Cai H, Xu Y, Wang X, Li RS, Shen T. [Clinical features of 76 Chinese patients with paroxysmal nocturnal haemoglobinuria]. Zhonghua Xue Ye Xue Za Zhi. 2012 Jun;33(6):471-4. 
11. Heller PG, Grinberg AR, Lencioni M, Molina MM, Roncoroni AJ. Pulmonary hypertension in paroxysmal nocturnal hemoglobinuria. Chest. 1992 Aug;102(2):642-3.

12. Nagarajan S, Brodsky RA, Young NS, Medof ME. Genetic defects underlying paroxysmal nocturnal hemoglobinuria that arises out of aplastic anemia. Blood. 1995 Dec 15;86(12):4656-61.

13. Pavlo J, Necas E. [Paroxysmal nocturnal hemoglobinuria and its association with aplastic anemia]. Cas Lek Cesk. 1998 Jul 13;137(14):419-23.

14. Sutherland DR, Illingworth A, Keeney M, Richards SJ. HighSensitivity Detection of PNH Red Blood Cells, Red Cell Precursors, and White Blood Cells. Curr Protoc Cytom. 2015 Apr 1;72:6.37.1-6.37.29.

15. Madkaikar M, Gupta M, Jijina F, Ghosh K. Paroxysmal nocturnal haemoglobinuria: diagnostic tests, advantages, \& limitations. Eur J Haematol. 2009 Dec 1;83(6):503-11.

16. Devalet B, Mullier F, Chatelain B, Dogné JM, Chatelain C. Pathophysiology, diagnosis, and treatment of paroxysmal nocturnal hemoglobinuria: a review. Eur J Haematol. 2015 Sep;95(3):190-8.

17. Preis M, Lowrey CH. Laboratory tests for paroxysmal nocturnal hemoglobinuria. Am J Hematol. 2014 Mar;89(3):339-41.

18. Kasper DL, Fauci AS, Hauser SL, Longo DL, Jameson JL, Loscalzo J. In: Harrison's Principles of Internal Medicine, $19^{\text {th }}$ edition $2015 ; 660-62$.

19. Pantin J, Tian X, Geller N, Ramos C, Cook L, Cho E, Scheinberg P, Vasu S, Khuu H, Stroncek D, Barrett J, Young NS, Donohue T, Childs RW. Long-term outcome of fludarabine-based reduced-intensity allogeneic hematopoietic cell transplantation for debilitating paroxysmal nocturnal hemoglobinuria. Biol Blood Marrow Transplant. 2014 Sep;20(9):1435-9.
20. Marotta S, Pagliuca S, Risitano AM. Hematopoietic stem cell transplantation for aplastic anemia and paroxysmal nocturnal hemoglobinuria: current evidence and recommendations. Expert Rev Hematol. 2014 Dec;7(6):775-89.

21. Santarone S, Bacigalupo A, Risitano AM, Tagliaferri E, Bartolomeo ED, Iori AP et al. Hematopoietic stem cell transplantation for paroxysmal nocturnal hemoglobinuria: long-term results of a retrospective study on behalf of the Gruppo Italiano Trapianto Midollo Osseo (GITMO) Haematologica. 2010 Jun;95(6): 983-988.

22. Matos-Fernandez NA, Abou Mourad YR, Caceres W, Kharfan-Dabaja MA. Current status of allogeneic hematopoietic stem cell transplantation for paroxysmal nocturnal hemoglobinuria. Biol Blood Marrow Transplant. 2009 Jun;15(6):656-61.

23. Pulini S, Marando L, Natale A, et al. Paroxysmal nocturnal hemoglobinuria after autologous stem cell transplantation: extinction of the clone during treatment with eculizumab pathophysiological implications of a unique clinical case. Acta Haematol. 2011;126(2):103-9.

24. Röth A, Dührsen U. Treatment of paroxysmal nocturnal hemoglobinuria in the era of eculizumab. Eur J Haematol. 2011 Dec;87(6):473-9.

25. Parker CJ. Management of paroxysmal nocturnal hemoglobinuria in the era of complement inhibitory therapy. Hematology Am Soc Hematol Educ Program. 2011;2011: 21-9.

26. Parker C. Eculizumab for paroxysmal nocturnal haemoglobinuria. Lancet. 2009 Feb 28;373(9665):759-67.

27. Struijk GH, Bouts AH, Rijkers GT, Kuin EA, ten Berge IJ, Bemelman FJ. Meningococcal sepsis complicating eculizumab treatment despite prior vaccination. Am J Transplant. 2013 Mar;13(3):819-20.

28. Hublikar S, Maher WE, Bazan JA. Disseminated gonococcal infection and eculizumab-a "high risk" connection? Sex Transm Dis. 2014 Dec;41(12):747-8. 